\title{
Craving and Depression in Opiate Dependent Mentally III African Americans Receiving Buprenorphine/Naloxone and Group CBT (Cognitive Behavioral Therapy)
}

\author{
Tanya Alim¹*, Suneeta Kumari ${ }^{1}$, Leslie Adams², Didier Anton Saint-Cyr ${ }^{1}$, Steve Tulin ${ }^{1}$, Elizabeth \\ Carpenter-Song ${ }^{3}$, Maria Hipolito ${ }^{1}$, Loretta Peterson ${ }^{1}$ and William B Lawson ${ }^{4}$
}

${ }^{1}$ Department of Psychiatry and Behavioral Sciences, College of Medicine, Howard University, USA

${ }^{2}$ Health Behavior Doctoral Student, University of North Carolina, United States

${ }^{3}$ Assistant Professor of Community and Family Medicine, Dartmouth Psychiatric Research Center (PRC), Geisel School of Medicine, United States

${ }^{4}$ Associate Dean for Health Disparities, Dell Medical School, The University of Texas, Texas

Corresponding author: Department of Psychiatry and Behavioral Sciences, College of Medicine, Howard University, Washington, D.C., USA, Tel: 202-865-3796; E-mail: talim@howard.edu

Received date: June 15, 2017; Accepted date: July 11, 2017; Published date: July 18, 2017

Copyright: (c) 2017 Alim T, et al. This is an open-access article distributed under the terms of the Creative Commons Attribution License, which permits unrestricted use, distribution, and reproduction in any medium, provided the original author and source are credited.

Citation: Alim T, Kumari S, Adams L, Saint-Cyr A, Tulin S, et al. Craving and Depression in Opiate Dependent Mentally III African Americans Receiving Buprenorphine/Naloxone and Group CBT (Cognitive Behavioral Therapy). Clin Psychiatry 2017, 3(2):11.

\section{Abstract}

Given limited research on patient perspectives, we sought to assess craving and depression in dually diagnosed African Americans receiving Buprenorphine/Naloxone and group therapy. Nineteen subjects were recruited and 13 completed the 12 month longitudinal study. Buprenorphine/Naloxone treatment and group therapy were provided weekly. Quarterly evaluations of craving, depression and patient perspectives of treatment were obtained. Craving, depression and reported opiate use significantly declined from baseline. Depression increased slightly at 12 months. Buprenorphine/Naloxone and group therapy resulted in a significant decrease in craving, depression severity, and reported opioid use with improvement in quality of life.

\section{Keywords: Craving; Opioid use; Depression;} Buprenorphine/Naloxone; Group therapy; African Americans

\section{Introduction}

Mental illness and substance use disorders are major global public health concerns $[1,2]$. The co-occurrence of severe mental illness (SMI) and substance use is common with approximately $50 \%$ of people with mental illness developing a substance use disorder [3]. Specifically, individuals with an opioid use disorder have a lifetime prevalence of any mood disorder of $54.2 \%$ or higher $[4,5]$.

Rates of substance use disorders are higher in African Americans who have SMI as compared with Euro-Americans or Latinos [6]. When SMI and substance use co-occur, they can lead to increased risk for psychiatric and substance use relapses, higher psychological distress, lower treatment retention and poor medication adherence $[7,8]$. Improved interventions for these clients are urgently needed, as the cost of treating cooccurring disorders is higher than mental illness alone [9], and current approaches have limited success and high rates of treatment failure $[10,11]$.

A key component in the maintenance of substance use and relapse is the person's craving for the drug. Craving has been defined as the subjective experience of the desire to use alcohol or drugs $[12,13]$. Craving has been found to be associated with depression. Zilberman, Tavares and el-Guebaly [14] found that craving scores were positively correlated with depression and negatively correlated with number of days abstinent from substance use.

In a study of patients detoxifying from alcohol in an inpatient setting, de Timary [15] found a positive correlation between depression and craving. Witkiewitz and Bowen [16] noted a strong relationship between negative affect and craving, with depressive symptomatology showing strong links to craving and substance abuse relapse. The relation between depression and substance use also results in the disproportionately higher rates of substance use relapse in individuals with affective disorders [17-19]. In other studies of depressed individuals, a strong relation was found between depressive symptoms and both craving and relapse [20-22]. Together, these studies suggest a link between craving, depression and relapse.

Opioid agonist pharmacotherapy, in combination with psychotherapy, can be clinically effective for the treatment of opioid use disorder [23]. Opioid addiction can be effectively treated with Buprenorphine/Naloxone (BUP/NAL) which was approved by the Food and Drug Administration [24]. BUP/NAL has been found to be effective in reducing craving when 
combined with psychotherapy [25]. Several studies also show that BUP/NAL reduces depressive symptoms as well $[26,27]$.

Qualitative studies evaluating BUP/NAL in patients are limited. In a study examining patient perspectives on BUP/NAL treatment in opioid users in the context of HIV care, patients reported improvement in substance use problem as well as their HIV care adherence [28]. Teruya [29] evaluated retention in patients being treated with opioid agonist therapies.

Our study sought to examine impact of BUP/NAL plus group psychotherapy in dually diagnosed African Americans on mood and craving from a quantitative and qualitative perspective.

\section{Methods}

\section{Procedures}

Written informed consent was obtained from all subjects. This study was funded by NIDRR Grant H133A080063 "Building Knowledge and Capacity in the Rehabilitation and Recovery of African-Americans suffering from severe mental illness." The study was approved by the university Institutional Review Board for the Protection of Human Subjects. Subjects were provided a \$25 gift card incentive for each visit.

\section{Study design}

The study employed a longitudinal, mixed-methods approach with baseline and weekly drug toxicology tests and weekly treatment interventions. Weekly group CBT was facilitated by a clinical social worker and a psychiatrist.

\section{Study sample}

The initial study sample consisted of 19 African-Americans who were diagnosed using DSM-IV criteria for current opioid dependence and SMI, with diagnoses including Bipolar Disorder, Major Depressive Disorder (several patients also had an anxiety disorder). In this study SMI was defined as a chronic and disabling psychiatric disorder. Subjects were recruited via waiting list for BUP/NAL treatment at a hospital mental health clinic in Washington, D.C., as well as by flyer and word of mouth. After successful enrollment, subjects received psychiatric care for their mental illness at Mental Health Clinic or by community providers in Washington, D.C.

All subjects reported showing recent opioid use for at least a month before starting BUP/NAL, confirmed by positive opioid toxicology. Thirteen subjects reported using intravenous heroin and 11 reported intranasal use (5 reported both). Subjects were excluded if unable to give informed consent, using pain narcotic medications or benzodiazepines, pregnant or lactating, or not using a reliable method of birth control.

Thirteen subjects completed the study. Of the 19 subjects who began the study, 2 did not return after baseline visit. Four were dismissed from the study and referred for more intensive treatment. For the following reasons: one of the 4 subjects was on pain narcotic medication and another was prescribed both pain narcotic medication and benzodiazepines by an outside provider. The other subject attended group while extremely intoxicated and the 4th person did not attend group CBT after 3 weeks.

Assessment of psychiatric disorders: Patients were interviewed with a modified Mini International Neuropsychiatric Interview (MINI), a brief diagnostic interview for psychiatric disorders [30].

Assessment of drug dependence: Addiction Severity Index Lite (ASI) was done at baseline and 12 months assessing past 30 day and lifetime alcohol and drug use, medical, psychiatric, family/social, employment, and legal problems. The ASI Lite is correlated with the full ASI [31].

Assessment of depression: The Patient Health Questionnaire (PHQ 9), a nine item scale was used to screen for depression and monitor treatment response [32] was done quarterly. The range of scores is from 0 to 27 . The severity of scores are the following: minimal depression (1 to 4); mild depression (5 to 9); moderate depression (10 to 14); moderately severe depression (15 to 19) and severe depression (20 to 27).

Assessment of craving: Intensity and frequency of craving were captured using the Brief Substance Craving Scale (BSCS) quarterly. The BSCS is a short version of the 16 item self-report instrument assessing craving for substances of abuse over a 24 hour period [33]. The range of scores reported is from 0 to 12 .

Assessment of treatment outcome (total days of opiate use): The Timeline Follow-back Method (TLFB) obtains information on drug consumption and duration using a calendar method on which the client estimates alcohol/drugs used on each occasion during a specific time period. TLFB was designed for alcohol consumption but has been validated for drug use [34]. TLFB was done quarterly and drug usage was assessed in the previous 90day time period.

Treatment adherence: Treatment adherence was defined by meeting two criteria: 1) taking BUP/NAL as prescribed and 2) positive toxicology screen for BUP/NAL for $80 \%$ of visits (Tkacz et al., 2011). Adherence to BUP/NAL was emphasized by encouraging patients to take medication throughout the study. Urine or cheek swabs were obtained weekly to assess illicit drug use and BUP/NAL adherence.

Assessment of subjective experience of co-occurring disorders and treatment: Qualitative interviews were conducted quarterly. Interviews explored subjects' experiences of mental illness and addiction, their experience of treatment, as well as its perceived impact on recovery covariates such as housing, community integration, and social support.

\section{Data Analysis}

Statistical analysis was performed using STATA IC version 13. Analysis of variance (ANOVA) was used to compare study subjects' mean depression and craving over the 12 months. We used generalized estimating equations (GEE) to test interaction between craving and depression across the 12 months and to account for missing data. The analyses controlled for age and gender. 


\section{Results}

\section{Patient characteristics}

Table 1 presents the socio-demographic and clinical features of the sample at baseline. The initial sample included 10 females and 9 males. On average, study participants completed 11.6 years of education. $74 \%$ had a generalized anxiety disorder, $58 \%$ had bipolar disorder and $42 \%$ had major depressive disorder (several subjects had multiple diagnoses). The average duration of heroin use was 23 years, with average recent use of 13 days out of the last 30 days. There was a significant reduction in the composite ASI drug score between baseline and 12 months $(0.29$ to $0.12, p<0.001)$. The average of dose of BUP/NAL was $24 \mathrm{mg} / 6$ mg per day.

Table 1 Characteristics of study participants $(N=19)$ in BUP/NAL trial.

\begin{tabular}{|c|c|}
\hline Characteristics & $\begin{array}{l}\text { Total group } \\
(\mathrm{N}=19)\end{array}$ \\
\hline Age, mean years [stdv] & $51.79[1.88]$ \\
\hline Gender, \% Female (n) & $52.63(10)$ \\
\hline \multicolumn{2}{|l|}{ Religion, \% (n) } \\
\hline Protestant & $21.05(4)$ \\
\hline Catholic & $21.05(4)$ \\
\hline Islamic & $10.53(2)$ \\
\hline Other & $36.84(7)$ \\
\hline None & $10.53(2)$ \\
\hline \multicolumn{2}{|l|}{ Education level, \% years $(n)$} \\
\hline Low to Moderate (0-10 yrs) & $21.05(4)$ \\
\hline High (11-15 yrs) & $78.95(15)$ \\
\hline \multicolumn{2}{|l|}{ Marital Status, \% (n) } \\
\hline Married & $21.43(3)$ \\
\hline Never married, widowed, divorced, separated & $78.57(11)$ \\
\hline \multicolumn{2}{|l|}{ Living Arrangements, \% (n) } \\
\hline Sexual partner + children & $5.26(1)$ \\
\hline Sexual partner alone & $10.53(2)$ \\
\hline Children alone & $10.53(2)$ \\
\hline Parents & $5.26(1)$ \\
\hline Other family & $31.58(6)$ \\
\hline Friends & $15.79(3)$ \\
\hline Alone & $21.05(4)$ \\
\hline \multicolumn{2}{|l|}{ Co-morbid disorders, $\%$ yes } \\
\hline Bipolar Disorder & $57.89(11)$ \\
\hline Anxiety Disorder & $73.68(14)$ \\
\hline Major Depressive Disorder & $42.11(8)$ \\
\hline
\end{tabular}

(C) Under License of Creative Commons Attribution 3.0 License

\begin{tabular}{|c|c|}
\hline Severe Mental IIIness, \% yes & $70.00(14)$ \\
\hline Living with someone with alcohol problems, \% yes & $22.22(4)$ \\
\hline $\begin{array}{l}\text { Living with someone using non-prescribed drugs, \% } \\
\text { yes }\end{array}$ & $22.22(4)$ \\
\hline \multicolumn{2}{|l|}{ Route of Heroin use, \% (n) } \\
\hline Oral & $3.57(1)$ \\
\hline Nasal & $39.29(11)$ \\
\hline Smoking & $7.14(2)$ \\
\hline Non-IV Injection & $3.57(1)$ \\
\hline IV & $46.43(13)$ \\
\hline \multicolumn{2}{|l|}{ Substance use in past thirty days, mean [stdv] } \\
\hline Heroin & $12.77[13.35]$ \\
\hline Alcohol & $7.47[5.51]$ \\
\hline Methadone & $1.23[5.51]$ \\
\hline Opiates & $1.46[5.96]$ \\
\hline Barbituates* & $0.23[1.28]$ \\
\hline Cocaine & $1.58[4.44]$ \\
\hline Cannabis & $1.1[5.47]$ \\
\hline \multicolumn{2}{|l|}{ Substance use over lifetime, mean in years [stdv] } \\
\hline Heroin & $23.00[14.41]$ \\
\hline Alcohol & $18.73[13.87]$ \\
\hline Methadone & $1.13[3.40]$ \\
\hline Opiates & 0.43 [2.19] \\
\hline Barbituates* & 1.03 [4.09] \\
\hline Cocaine & 8.87 [12.46] \\
\hline Cannabis & $7.52[14.78]$ \\
\hline
\end{tabular}

\section{Depression severity}

PHQ-9 scores declined from 18.1 at baseline (moderately severe to severe) to 8.3 (mild to moderate) at the 9 months' follow-up $(p<0.05)$. Absolute depression scores showed a nonsignificant increase at 12 months to 10.8 (moderate). The decline of depression severity over time among study subjects was significant $(p=0.002)$.

\section{Craving}

At baseline subjects had an average craving score of 8.6 out of 10. Craving scores declined from 8.6 to 5.1 from baseline to month 12. Changes in craving between the 9 to 12 months' period were not significant. The overall decline in craving from baseline to 12 months was significant $(p<0.001)$.

\section{Reported Total Days of Opiate Use}

Figure 1 depicts total days of opiate use over time using the TLFB. Based on the TLFB (assessing the last 90 days of use) selfreported total days of opiate use declined during the study, from 
73.2 days at baseline to 1 day at 9 months. The greatest reduction occurred between baseline and 3 months (73.2 to 4.5 days, $p<0.001)$. There was an increase in use between 9 and 12 months ( 1 to 6.8 days, $p<0.001$ ).

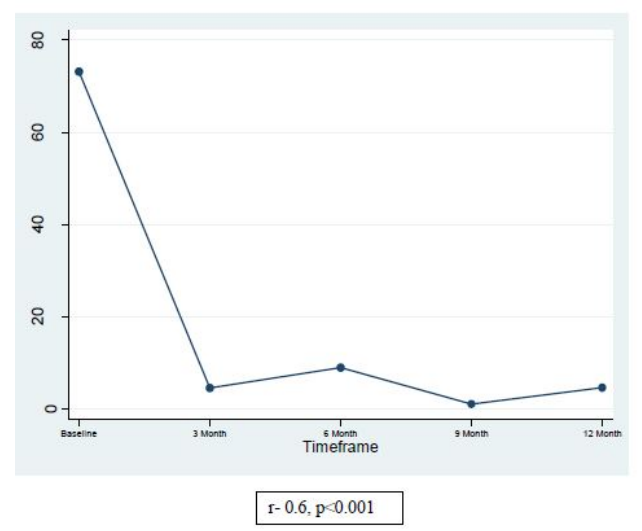

Figure 1 Mean total days of opiate use over time (TLFB).

\section{Treatment adherence}

Initially, the total sample size for this study was 20 patients, however, lab data for 7 participants were not included in final analysis due to early termination or missing data. We calculated percentages of positive toxicology to drugs at baseline and at quarterly visits.

Based on our definition of adherence stated earlier, 53\% (7) of the patients were compliant with BUP/NAL treatment over time and $92 \%$ were positive for BUP/NAL at quarterly visits.

The results from the toxicology data show those participants who were non-compliant with BUP/NAL treatment also used other illicit drugs (cocaine, marijuana, PCP) in addition to opioids. Table 2 shows a summary of the results.

Table 2 Toxicology result.

\begin{tabular}{|l|l|}
\hline Toxicology Result & $\%(\mathbf{N})$ \\
\hline Mean Quarterly BUP/NAL Positive & $92.30 \%(12)$ \\
\hline Adherent with BUP/NAL Treatment & $53.84 \%(7)$ \\
\hline Opioid Positive (Codeine, Morphine) & $46.15 \%(6)$ \\
\hline Cocaine Positive & $38.46 \%(5)$ \\
\hline Marijuana Positive & $23.07 \%(3)$ \\
\hline PCP Positive & $7.69 \%(1)$ \\
\hline
\end{tabular}

\section{Subjective experiences of participants}

Subjects reported a decline in craving frequency and intensity over the course of the study. Prior to this change many subjects reported frequent substance use as part of their daily routines. Subjects described heroin craving at baseline as pervasive in their daily lives before entering the study.
At the 3 and 6 month follow-up subjects described a decline in many of the thoughts associated with opiate use and the shifting of their priorities towards recovery. One participant stated, "It (Suboxone) stopped my cravings, my desire to use. It helps a lot with the withdrawal symptoms of the opiates. And you really don't think about using that much". Subjects noted some side effects of BUP/NAL that were a barrier to its use, including dry mouth, headache and lack of energy.

By 9 and 12 months, qualitative responses mirrored the quantitative reductions in craving with a reduced overall need for opiates and a more positive approach towards recovery, with more upbeat tone and attitude. Subjects also reported increased clarity of thinking over time and less intrusive thoughts regarding substance use.

Two subjects spoke about their progress related to craving in the final months of the study. One stated, "It's (Suboxone) keeping the desire to use, it's keeping me away from it, I don't think about it, I'm not tempted anymore, I'm taking my Suboxone and I'm happy. Don't want it (heroin), taking away the dope sickness in the morning time. I have happy feelings, it has affected tremendously, I don't have the desire very, very, very, very less craving, so it's no, I don't want it, I don't crave for it that world is gone"

Another stated, "Everything is alright with me now, I'm taking my medication as prescribed. I don't do it (heroin) anymore and I feel good about that. Suboxone helps me with my drug use and my thoughts are clear. My energy is not where I want but it's much better."

In addition to noting a reduction in craving, many subjects noted increased hope of recovery from substance use. Subjects who completed 12 months also attributed their reduction in opiate use to family support and religious influences. As subjects began to have reduced craving, employment was mentioned more frequently as a method of improving overall recovery. Many felt that having a stable job would remove them from the tempting environments that initiated substance use and further reduce cravings.

\section{Generalized Equation Modeling and Correlation Analysis}

Higher craving scores and depression severity were positively associated, suggesting that improving mental health may be linked to decreased opiate craving or the treatment intervention was effective for both $(r=0.63, p<0.001$, Figure 2). Crude GEE analysis displayed a significant association between craving score and depression $(\beta=0.22, \quad p<0.001)$. After adjustment, results of the GEE analysis supported the association between lower craving scores and observed decreases in depression severity $(\beta=0.23, p<0.001)$. Both age and gender had a nonsignificant impact on craving score.

\section{Discussion}

Craving scores and depression ratings declined significantly from baseline to 12 months overall. Moreover, they were 
correlated and both were associated with a decrease in substance use. A slight increase in craving, depression and use of opioids was observed from 9 months to 12 months. Selfreported drug use reported between months 9 and 12 on TLFB is consistent with our preliminary drug toxicology results. While we are uncertain of the cause of this increase, it may be consistent with the phenomenon of "slipping" in recovery from drug use [35-37]. The finding that an increase in craving was associated with an increase in depression is consistent with Zilberman [14,21], de Timary [15] and Witkiewitz and Bowen [16]. ASI scores showed improvement in drug use. These results suggest that both medication assisted therapy and psychotherapy can be an effective treatment for dually diagnosed African American patients.

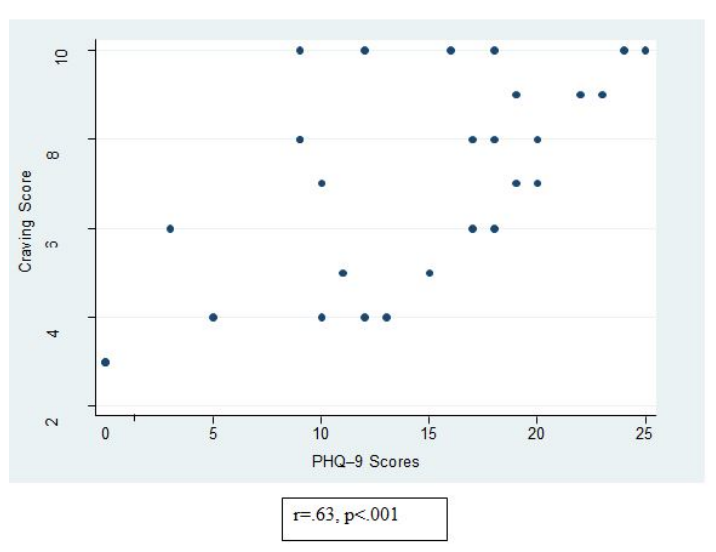

Figure 2 Correlation of craving and depression severity (PHQ-9).

\section{Limitations}

The study had several limitations. The sample for this study is drawn from the Metropolitan Washington, D.C. area and is African American, thus results may not be generalizable to other outpatient settings where patients receive BUP/NAL maintenance treatment, to non-African Americans, or to populations in suburban and rural areas. Additionally, due to the small sample size, comparative analyses were underpowered. Given these limitations, it is important not to understate the significance of these findings.

To our knowledge, this is the first study that preliminarily examined quantitative and qualitative factors associated with the treatment of dually diagnosed African Americans on BUP/NAL and group psychotherapy. Based on the findings from this study, future well-designed, larger sampled, prospective studies may help to better understand mental health and substance use recovery of individuals with mental illness and opioid use disorders in African Americans and other minority groups to determine if these differences are race specific and if these results are persistent. The results may also generalize to non-minority populations, whose use of opioids has become an increasing challenge.

\section{Acknowledgements}

"Building Knowledge and Capacity in The Rehabilitation and Recovery of African-Americans Suffering from Severe Mental Illness: The Dartmouth-Howard Collaboration" (NIDRR RRTC H133A080063; PI: Whitley), Rebeka Nazneen, Samuel Odedokun, Ali Raza and Mental Health Clinic staff.

\section{Disclosures}

Drs. Saint-Cyr, Tulin, Carpenter-Song report, Ms. Adams and Ms. Peterson have no financial relationships with commercial interests. Dr. Alim had a financial relationship with Otsuka Pharmaceutical, Inc. Dr. Lawson had a financial relationship with Merck, Inc. and Ostuka Pharmaceuticals, Inc. The authors have no additional income to report.

\section{References}

1. Kessler RC (2004) The epidemiology of dual diagnosis. Biological Psychiatry 56: 730-737.

2. Kessler RC, Aguilar-Gaxiola S, Alonso J, Chatterji S, Lee S, et al. (2009) The global burden of mental disorders: An update from the WHO World Mental Health (WMH) Surveys. Epidemiologia e Psichiatria Sociale 18: 23-33.

3. Mueser KT, Bennett M, Kushner MG (1995) Epidemiology of substance use disorders among persons with chronic mental illnesses. Chronic Mental Illness and Substance Use Disorders : 9-25.

4. Conway KP, Compton W, Stinson FS, Grant BF (2006) Lifetime Comorbidity of DSM-IV Mood and Anxiety Disorders and Specific Drug Use Disorders: Results from the National Epidemiologic Survey on Alcohol and Related Conditions. J Clin Psychiatry 67: 247-257.

5. Doolittle B, Becker W (2011) A Case Series of Buprenorphine/ Naloxone Treatment in a Primary Care Practice. Subst Abus 32: 262-265.

6. Hatzenbuehler ML, Keyes KM, Narrow WE, Grant BF, Hasin DS (2008) Racial/Ethnic Disparities in Service Utilization for Individuals With Co-Occurring Mental Health and Substance Use Disorders in the General Population. J Clin Psychiatry 69: 1112-1121.

7. Mueser KT, Drake RE, Wallach MA (1998) Dual diagnosis: A review of etiological theories. Addictive Behaviors 23: 717-734.

8. Ziedonis DM, Smelson D, Rosenthal RN, Batki SL, Green Al, et al. (2005) Improving the Care of Individuals with Schizophrenia and Substance Use Disorders: Consensus Recommendations. J Clin Psychiatry 11: 315-339.

9. Mark TL (2003) Economic Grand Rounds: The Costs of Treating Persons with Depression and Alcoholism Compared with Depression Alone. Psychiatric Services 54: 1095-1097.

10. Horsfall J, Cleary M, Hunt GE, Walter G (2009) Psychosocial treatments for People with Co-Occurring Severe Mental Illnesses and Substance Use Disorders (Dual Diagnosis): A Review of Empirical Evidence. Harv Rev Psychiatry 17: 24-34.

11. Satcher DS (2000) Executive summary: a report of the surgeon general on mental health. Public Health Reports 115: 89-101. 
12. Sayette MA, Shiffman S, Tiffany ST, Niaura RS, Martin CS, et al. (2000) The measurement of drug craving. Addiction 95: 189-210.

13. Tiffany ST (1990) A cognitive model of drug urges and drug-use behavior: Role of automatic and nonautomatic processes. Psychological Review 97: 147-168.

14. Zilberman ML, Tavares H, el-Guebaly N (2003) Relationship between craving and personality in treatment-seeking women with substance-related disorders. BMC Psychiatry 3: 1.

15. de Timary P, Cordovil de Sousa Uva M, Denoël C, Hebborn L, Derely M, et al. (2013) The Associations between SelfConsciousness, Depressive State and Craving to Drink among Alcohol Dependent Patients Undergoing Protracted Withdrawal. Plos One 8: e71560.

16. Witkiewitz K, Bowen S (2010) Depression, craving, and substance use following a randomized trial of mindfulness-based relapse prevention. J Consult Clin Psychol 78: 362-374.

17. Conner KR, Sorensen S, Leonard KE (2005) Initial depression and subsequent drinking during alcoholism treatment. J Stud Alcohol 66: 401-406.

18. Hasin DS, Grant BF (2002) Major Depression in 6050 Former Drinkers. Arch Gen Psychiatry 59: 794-800.

19. Kodl MM, Fu SS, Willenbring ML, Gravely A, Nelson DB, et al. (2008) The Impact of Depressive Symptoms on Alcohol and Cigarette Consumption Following Treatment for Alcohol and Nicotine Dependence. Alcohol Clin Exp Res 32: 92-99.

20. Gordon SM, Sterling R, Siatkowski C, Raively K, Weinstein S, et al. (2006) Inpatient Desire to Drink as a Predictor of Relapse to Alcohol Use Following Treatment. Am J Addict: 15: 242-245.

21. Zilberman ML, Tavares H, Hodgins DC, el-Guebaly N (2007) The Impact of Gender, Depression, and Personality on Cravings. J Addict Dis 26: 79-84.

22. Curran GM, Flynn HA, Kirchner J, Booth BM (2000) Depression after alcohol treatment as a risk factor for relapse among male veterans. J Subst Abuse Treat 19: 259-265.

23. Fudala PJ, Bridge TP, Herbert $S$, Williford WO, Chiang CN, et al. (2003) Office-Based Treatment of Opiate Addiction with a Sublingual-Tablet Formulation of Buprenorphine and Naloxone. N Engl J Med 349: 949-958.

24. FDA (2002) Subutex and Suboxone Approved to Treat Opiate Dependence.

25. Springer SA, Chen S, Altice FL (2010) Improved HIV and Substance Abuse Treatment Outcomes for Released HIV-Infected Prisoners:
The Impact of Buprenorphine Treatment. J Urban Health 87: 592-602.

26. Demetrovics Z, Farkas J, Csorba J, Németh A, Mervó B, et al. (2009) Early experience with Suboxone maintenance therapy in Hungary. Neuropsychopharmacol Hung 11: 249-257.

27. Petke Z, Csorba J, Meszaros J, Vingender I, Farkas J, et al. (2012) Changes in psychosocial symptoms of opiate users over six months with buprenorphine/naloxone substitution therapy. Neuropsychopharmacol Hung 14: 7-17.

28. Egan JE, Netherland J, Gass J, Finkelstein R, Weiss L (2011) Patient Perspectives on Buprenorphine/Naloxone Treatment in the Context of HIV care. J Acquir Immune Defic Syndr 56: S46-S53.

29. Teruya C, Schwartz RP, Mitchell SG, Hasson AL, Thomas C, et al. (2014) Patient Perspectives on Buprenorphine/Naloxone: A Qualitative Study of Retention During the Starting Treatment with Agonist Replacement Therapies (START) Study. J Psychoactive Drugs 46: 412-426.

30. Sheehan DV, Lecrubier Y, Sheehan KH, Amorim P, Janavs J, et al. (1998) The Mini-International Neuropsychiatric Interview (M.I.N.I.): the development and validation of a structured diagnostic psychiatric interview for DSM-IV and ICD-10. J Clin Psychol 59: 22-33.

31. Cacciola JS, Alterman AI, McLellan AT, Lin YT, Lynch KG (2007) Initial evidence for the reliability and validity of a "Lite" version of the Addiction Severity Index. Drug Alcohol Depend: 87: 297-302.

32. Kroenke K, Spitzer RL, Williams JB (2001) The PHQ-9: Validity of a Brief Depression Severity Measure. J Gen Intern Med 16: 606-613.

33. Somoza E, Dyrenforth S, Goldsmith J, Mezinskis J, Cohen M (1995) In Search of a Universal Drug Craving Scale. Paper presented at the Annual Meeting of the American Psychiatric Association, Miami, Florida.

34. Carey KB, Correia CJ (1998) Severe mental illness and addictions: assessment considerations. Addict Behav 23: 735-748.

35. O'Brien CP, Childress AR, McLellan T, Ehrman R (1990) Integrating systemic cue exposure with standard treatment in recovering drug dependent patients. Addict Behav 15: 355-365.

36. Tiffany ST, Carter BL, Singleton EG (2000) Challenges in the manipulation, assessment and interpretation of craving relevant variables. Addiction 95: 177-87.

37. Tkacz J, Severt J, Cacciola J, Ruetsch C (2011) Compliance with Buprenorphine Medication-Assisted Treatment and Relapse to Opioid Use. Am J Addict 21: 55-62. 